\title{
Structural Design of a Jacket Platform to the Colombian Caribbean Sea
}

Jairo H. Cabrera ${ }^{1}$

Jair Macía Ávilar ${ }^{2}$

\begin{abstract}
This research paper summarizes the study of the requirements and basic theoretical foundation for the development of structural design of fixed platform type Jacket, resulting in the proposal for a analysis model for this type of offshore structure. Aspects related with cinematics evaluation, selecting of wave theory and hydrodynamic proper formula are also considered in the calculation of acting forces and the need for local metocean data in the analysis. A case study of application of the model for a new type structure jacket RC-5 Block of the Colombian Caribbean is also presented including its geometry proposed and some results of the numerical model procedures.
\end{abstract}

Key words: Jacket Offshore Platform; Structural Analysis and Design.

\section{Resumen}

Este trabajo de investigación resume el estudio de los requerimientos y fundamentos teóricos básicos necesarios para el desarrollo del diseño estructural de una plataforma offshore fija tipo Jacket, resultando en la propuesta de un modelo de análisis propio para este tipo de estructuras. Aspectos relacionados con las evaluaciones cinemáticas, selección de la teoría de ola y de la formulación hidrodinámica adecuada son igualmente considerados en el cálculo de las fuerzas actuantes así como en la necesidad de datos meteomarinos de local de análisis. Un caso estudio de aplicación del modelo para una nueva estructura tipo Jacket en el bloque RC-5 del Caribe Colombiano es igualmente presentado incluyendo geometría propuesta y algunos resultados de los procedimientos numéricos del modelo.

Palabras claves: Plataforma Offshore Jacket; Análisis Estructural y Diseño.

Date Received: January $13^{\text {th }} 2016$ - Fecha de recepción: Enero 13 de 2016

Date Accepted: May 25 th 2016 - Fecha de aceptación: Mayo 25 de 2016

\footnotetext{
${ }^{1}$ Universidad Tecnológica de Bolívar, Faculty of Engineering. Cartagena de Indias, Colombia. e-mail: jcabrera@unitecnologica.edu.co

${ }^{2}$ Universidad Tecnológica de Bolívar, Faculty of Engineering. Cartagena de Indias, Colombia. e-mail: jairmacia@gmail.com
} 


\section{Introduction}

A platform type Jacket is a structure placed on the ocean, built with steel tubular components and fixed at the bottom of the seabed with stakes, used for the exploration and specially for the production of hydrocarbons and mainly for depths of up to 300 meters. Structures that are exposed to the action of the waves, ocean currents, winds, earthquakes and other environmental aspects specific to the site operation and to be considered in the design.

Due to the large demand of hydrocarbons in the world, there is a need to explore new deposits in search for reserves, and consequently, its vast seas are becoming a promising frontier for exploration operations and a source of energy resources, projects known as offshore.

Colombia is not indifferent to these initiatives, since the 2007 Caribbean Round until the last 2014 Colombia Round, a total of 23 offshore contracts have been assigned, of which 21 are in the Colombian Caribbean sea, 13 of them are oriented to the exploration and production of hydrocarbons $(\mathrm{ANH})$.

The main objective of this research paper is to propose a model of analysis in the design of a platform type Jacket offshore considering the characteristics and conditions of loads produced by the environmental effects of the Colombian Caribbean sea. Define the guidelines and basic theoretical foundations to follow in the analysis and design of these types of structures, determining the actions of the environmental loads specific to the region of operation. Establish the procedures and methodologies for analysis and their corresponding design and regulatory criteria for the structures type Jacket with a case study application for the Colombian Caribbean Sea.

\section{Theoretical Reference}

There are various configurations for structural settings for the structures type Jacket depending on their installation and performance with respect to the environmental conditions and particularly to the seismic activities of a specific region, as shown in Fig. 1 [7].

Fig. 1. Structural Configuration [7].
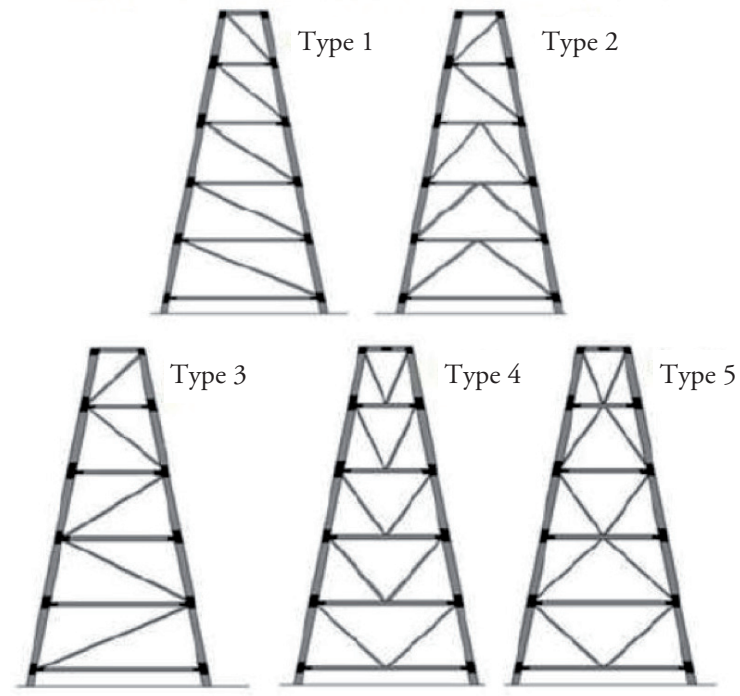

For the analysis of environmental forces on a structure type Jacket, the loads to which the sea based platform is exposed are evaluated. Therefore, the calculations of the environmental forces should not be made based solely on the estimations of the maximum loads on the structure, representing extreme situations like a tsunami, hurricane, earthquakes, storms, etc.; which directly affect the environmental forces increasing them with a factor up to five times the value of the normal operational loads.

From the point of view of the cinematics of water particles we have bidimensional models that work as a starting point for the estimation of the status of the sea based on the following classic theory of waves [5], among others:

- Stream Function

- Stokes of $5^{\circ}$ order.

- Linear wave or Airy

Fig. 2 (figure 2.3.1-3 of section 2 of API RP2AWSD), shows the regions of application of the theory of waves mentioned in the above list.

The most widely used theory and because of its simplicity is the linear theory of Airy, given that 
Fig. 2. Selection of the theory of waves [3].

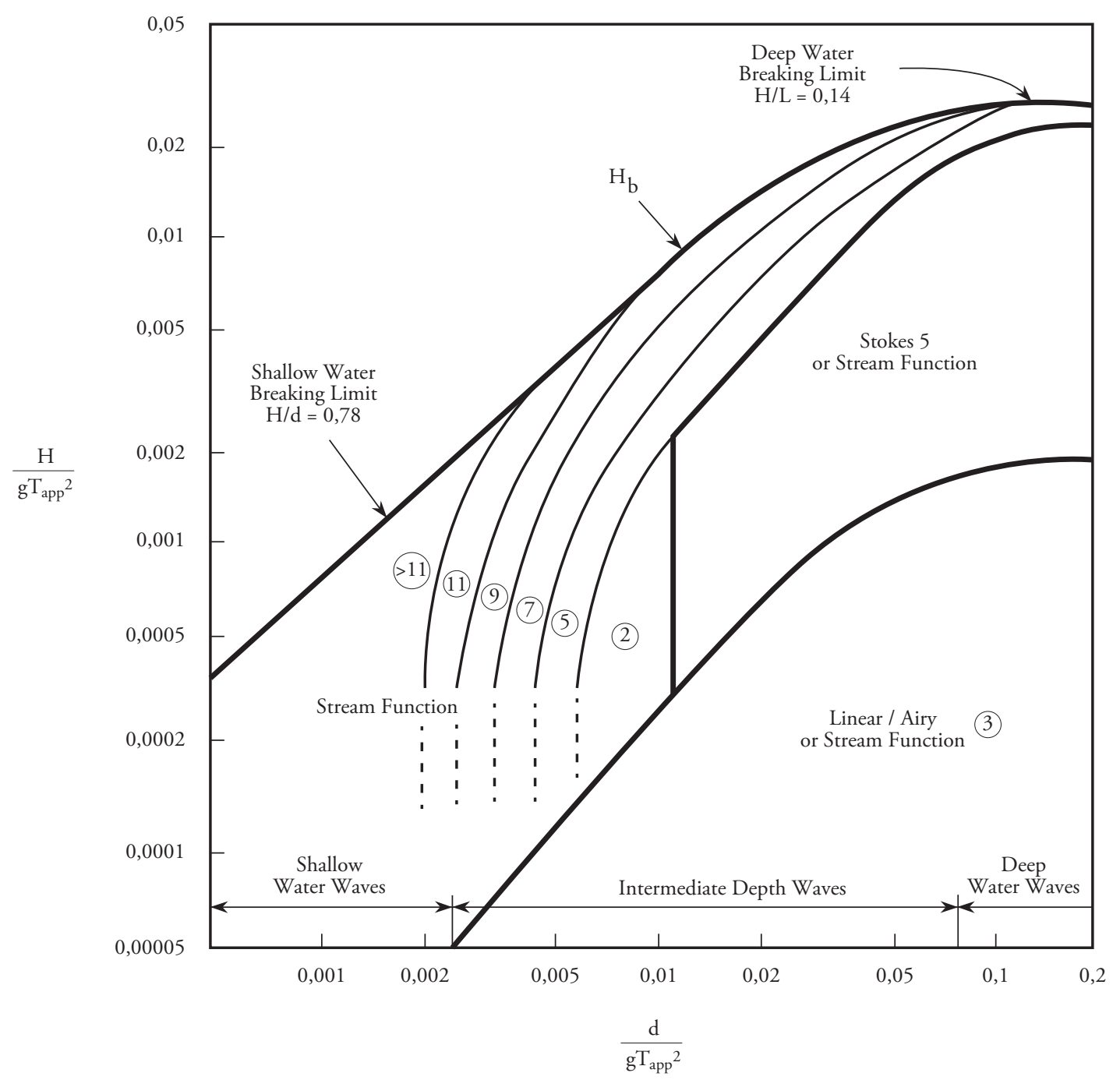

$\begin{array}{llll}\mathrm{H} / \mathrm{gT}_{\text {app }}{ }^{2} \text { : Dimensionless wave steepness } & \mathrm{H} \text { : Wave height } & \mathrm{d} \text { : Mean water depth } & \mathrm{g} \text { : Acceleration of gravity } \\ \mathrm{d} / \mathrm{gT}_{\text {app }}{ }^{2} \text { : Dimensionless relative depth } & \mathrm{H}_{\mathrm{b}} \text { : Breaking wave height } & \mathrm{T}_{\text {app }} \text { : Wave period } & \end{array}$

the origin of his formula is based on the potential $K=$ number of wave.

of speeds, which depend on the position of the $d=$ height of sheet of water.

particle in the fluid and the given $t$ that is taken as a reference. See equation 1.

$\varnothing(z, y, t)=\frac{A^{*} G}{w} * \frac{\cosh K(y+d)}{\sinh \left(K^{*} d\right)} * \sin K * x-w * t$

Where:

The hydrodynamic forces on the structural elements due to the action of the waves can be estimated in three different forms [2]:

- Morison Equation

- Froude- Krylov Theory

- Diffraction Theory

$A=$ wave width .

$g=$ gravity acceleration.

$w=$ frequency of the wave $(\mathrm{rad} / \mathrm{s})$.

According to the foregoing, when a structural element has a small relationship between the 
significant length (being such length the diameter in the case of cylinders) and the length of the wave tide (according Fig. 3), said element does not significantly prevent the propagation of the incident wave, therefore, it is possible to use the Morison equation for the calculation of the hydrodynamic forces on slim cylinders. This is the case in the majority of steel platforms type Jacket, where the structural elements usually do not exceed two meter diameters, against wave lengths that are generally larger than one hundred meters in the design waves.

In the Morison Equation, equation 2, the acting force has two components participating simultaneously, the terms of inertia and drag. This calculation can be applied when the structure is small with respect to the length of the tide wave. [2].

$$
\begin{gathered}
F=C_{D} * \rho * \frac{D}{2} *|u| * u+\left(C_{M}-1\right) * \pi \\
* \rho * \frac{D^{2}}{4} * \dot{u}+\pi * \rho * \frac{D^{2}}{4} * u
\end{gathered}
$$

Being that these are the main loads that determine the life cycle of a structure, the models and processes must be studied with detail to determine the limitations produced by each one considering the different codes that seek the design of an optimal structure for different environmental conditions.

In relation to the wind forces, the general expression is used for the calculation of said action over any structure located on the sea, represented by the equation 3.

Fig. 3. Regions to determine the hydrodynamic force formulation theory [3].

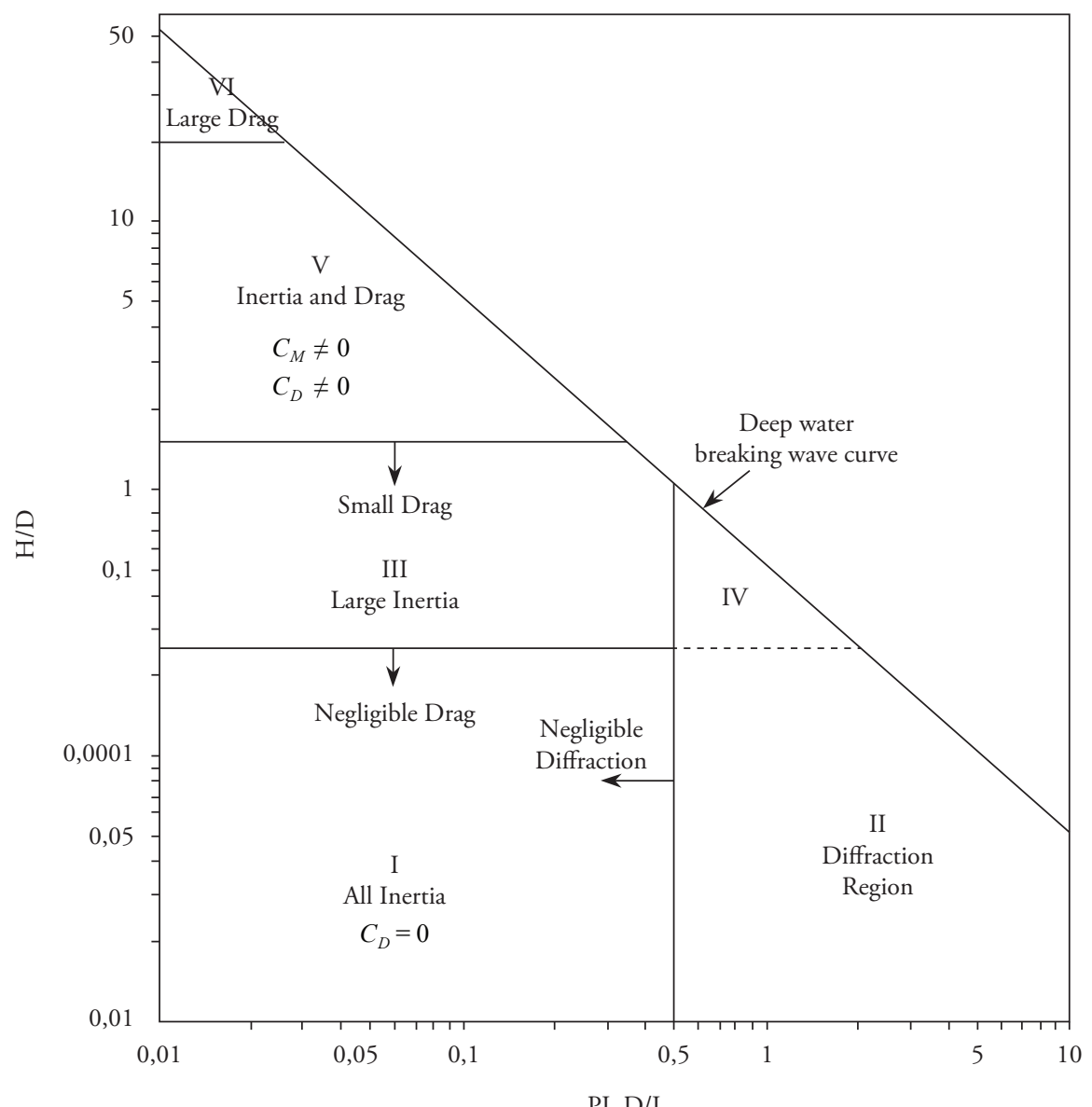

PI. D/L 


$$
F_{v}=C_{v} * \frac{\rho}{2} * V_{v}^{2} * A_{v}
$$

Where:

$F_{v}=$ Wind force.

$C_{v}^{v}=$ Wind Coefficient.

$V_{v}=$ Wind speed.

$A_{v}=$ Projected area of the surfaces in which it is found

The value of the wind coefficient is represented by a factor of the form of the structure and the factor depending on the height of the affected part of the structure, according equation 4 .

$$
C_{v}=C_{s} * C_{h}
$$

Where:

$C_{s}=$ Coefficient of Form (see table 1)

$C_{h}=$ Coefficient of Height (see table 2)

\begin{tabular}{|c|c|}
\hline Values for Cs & \\
\hline Form & Value \\
\hline Spheres & 0.4 \\
\hline Cylinder Forms (all sizes) & 0.5 \\
\hline Hull (type of surface) & 1.0 \\
\hline Superstructure & 1.0 \\
\hline Isolated structures (cranes, beams, bridges, tc) & 1.5 \\
\hline Areas under cover (smooth surface) & 1.0 \\
\hline Areas under cover (beam and length) & 1.3 \\
\hline Davit, crane gears (each face) & 1.3 \\
\hline
\end{tabular}

Table 1. Values for Coefficients of Form according to ABS.

In the estimation of the loads by the presence of ocean currents, the classic expression of an immersed element of a floating structure is used, equation 5.

$$
F_{c}=C_{d} * \frac{\rho_{s}}{2} * V_{v}^{2} * A_{c}
$$

Where:

$F_{c}=$ Force of current.

$C_{d}=$ Drag coefficient.
$A_{c}=$ Area of the surface that is against the current. $\left(\mathrm{m}^{2}\right)$.

$V_{c}=$ Speed of the current.

$\rho_{s}=$ Water density $\left(1,025-1,040 \mathrm{Kg} / \mathrm{m}^{3}\right)$.

The tubular components of the Offshore structures type Jacket are designed and verified against the admissible tensions and limit status in accordance with a series of codes applicable to the sector, mainly for these structures of the American Petroleum Institute (API). Codes that not only include resistance and functionality requirements, as well as additional structural behavior aspects plus complexes, such as hydrostatic collapse, punching sheer and resistance to damages from fatigue. The foregoing corresponds to one of the most relevant stages of the design process, providing a reasonable level of reliability during the life cycle provided for

\begin{tabular}{|c|c|c|}
\hline Altura (metros) & Altura (pies) & $\mathrm{Ch}$ \\
\hline $0,0-15,3$ & $0-50$ & 1,00 \\
\hline $15,3-30,5$ & $50-100$ & 1,10 \\
\hline $30,5-46,0$ & $100-150$ & 1,20 \\
\hline $46,0-61,0$ & $150-200$ & 1,30 \\
\hline $61,0-76,0$ & $200-250$ & 1,37 \\
\hline $76,0-91,5$ & $250-300$ & 1,43 \\
\hline $91,5-106,5$ & $300-350$ & 1,48 \\
\hline $106,5-122,0$ & $350-400$ & 1,52 \\
\hline $122,0-137,0$ & $400-450$ & 1,56 \\
\hline $137,0-152,5$ & $450-500$ & 1,60 \\
\hline $152,5-167,5$ & $500-550$ & 1,63 \\
\hline $167,5-183,0$ & $550-600$ & 1,67 \\
\hline $183,0-198,0$ & $600-650$ & 1,70 \\
\hline $198,0-213,5$ & $650-700$ & 1,72 \\
\hline $213,5-228,5$ & $700-750$ & 1,75 \\
\hline $228,5-244,0$ & $750-800$ & 1,77 \\
\hline $244,0-256,0$ & $800-850$ & 1,79 \\
\hline 256,0 & 850 & 1,80 \\
\hline
\end{tabular}
the structural components.

Table 2. Values for correction by height according to ABS.

The application of some codes in the design and checks towards the hydrocarbon sector in components of metallic structures as follows:

- APIOCT84 (API 15th Edition Code Check)

- 87APIH (API 17th Edition Hydrostatic Checks) 
Fig. 4. Model of Analysis.

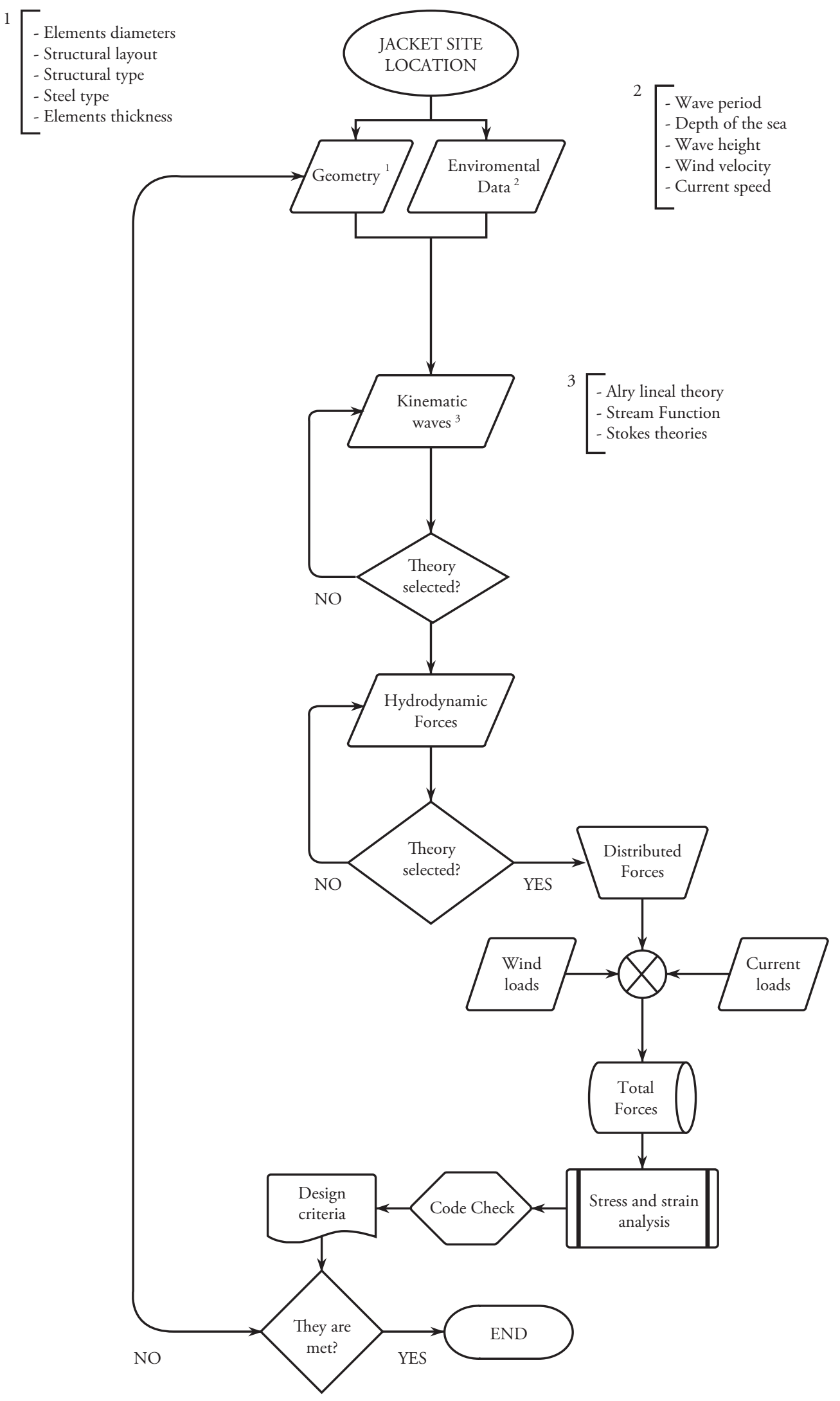


- $\quad$ APIH (API 8th Edition Hydrostatic Checks)

- 84NS3472 (1984, Norwegean Standard NS3472 E)

- APIWSD20 (API 20th Edition Code Check)

- $00 B S 5950$ (2000, British Standard BS 5950-1)

- 19902-07 (2007-12-01, ISO 19902 E, Petroleum and Natural Gas Industries Fixed Steel Offshore Structures First Edition)

- AISC13 (American Institute of Steel Construction AISC Thirteenth Edition)

- APIWSD21 (American Petroleum Institute,Working Stress Design, 21th Edition, December 2000)

- ASCE4805 (American Society of Civil Engineers, 2005 Edition)

- ASD9-E (based on AISC, 1989)

- EC3-2005 (Eurocode 3: Design of Steel Structures)

- IS800 (Indian Standard IS:800-1984)

- LFRD3 (AISC Load and Resistance Factor Design Third Edition)

- N690-94 (ANSI/AISC N690 1994 Edition)

- NF-2004 and NF-2007 (ASME-Section III, Division 1 - Subsection NF 2004 and 2007 Editions).

\section{Methodology}

Fig. 5 details the model of analysis for the structural design of platforms type Jacket applied to the Colombian Caribbean sea. Considering its location for operation, it is determined that the environmental characteristics corresponding to the adequate depth ranges for these types of structures.

The dimensions and geometry, and structural arrangement of the unit, will likewise depend on the environmental conditions, seismic conditions of the seabed as well as on the capacities destined to exploration and/or production of the field, distance to land or exploration system selected.

In the evaluation of the hydrostatic and hydrodynamic loads it is necessary to select the adequate wave theory having previously studied the aspects related to the cinematics of particles.

They are likewise included as one of the most important stages of the process of application of design and check codes.

Fig. 5. Location Block RC5 Pozo Mapale1 en Galerazamba, Colombian Caribbean [4].

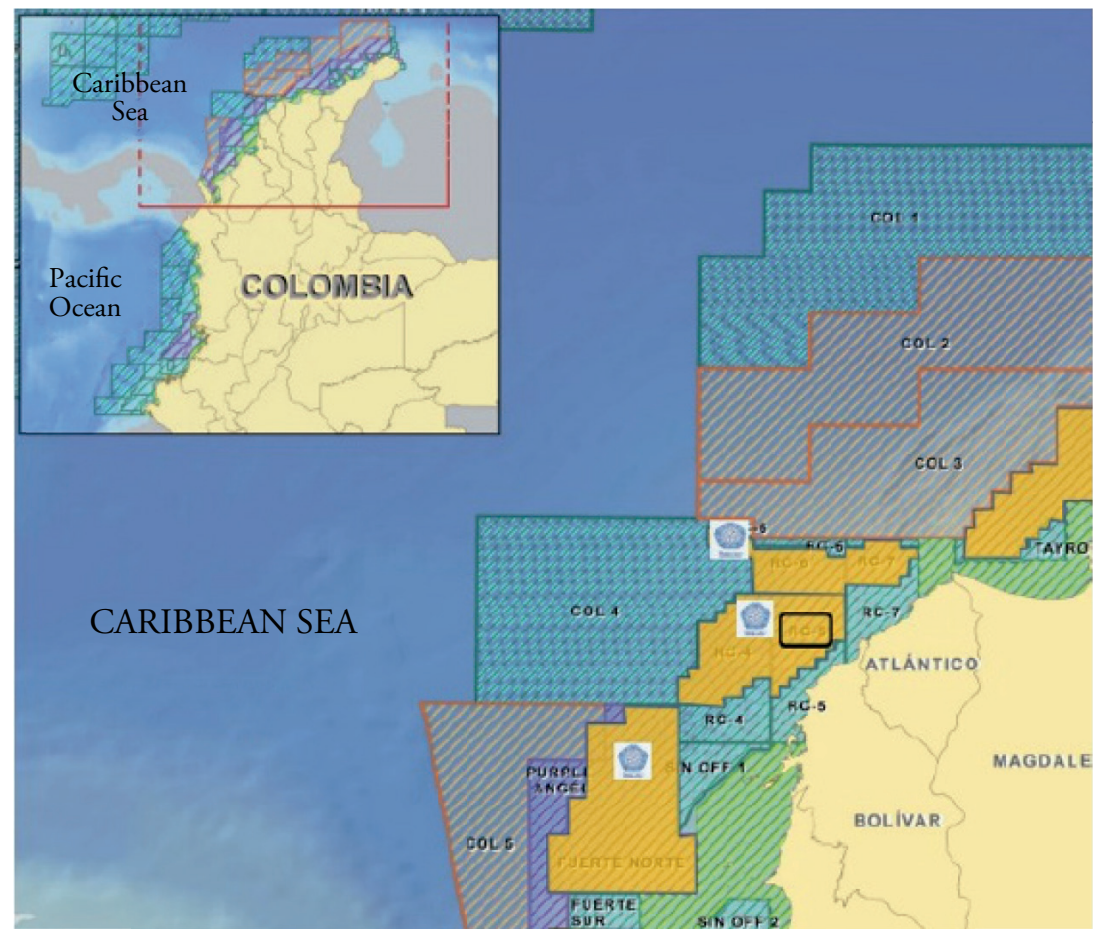




\section{Results}

As application of the proposed methodology, a study case of structural design was carried out on a new platform to be located in block RC-5 of the Colombian Caribbean sea, Fig. 5. A structural arrangement type 3 is selected, Fig. 1, in accordance with the characteristics and environmental conditions, particularly low depth and minimum seismic activity in the region, wave characteristics represented in Table 3.

In the calculation of the environmental loads and the analysis and check of the structural components, we relied on the GTSTRULD Y GTSELOS System [7], obtaining the permitted deformation results, Figure 6 and resistance, which were verified through standard API 2A-WSD. As shown in Fig. 7, no member exceeds the limit percentage of the load.

To evaluate the behavior of the platform a stiffness analysis is performed considering the interaction

Fig. 6. Maximum movement in nodes [7].

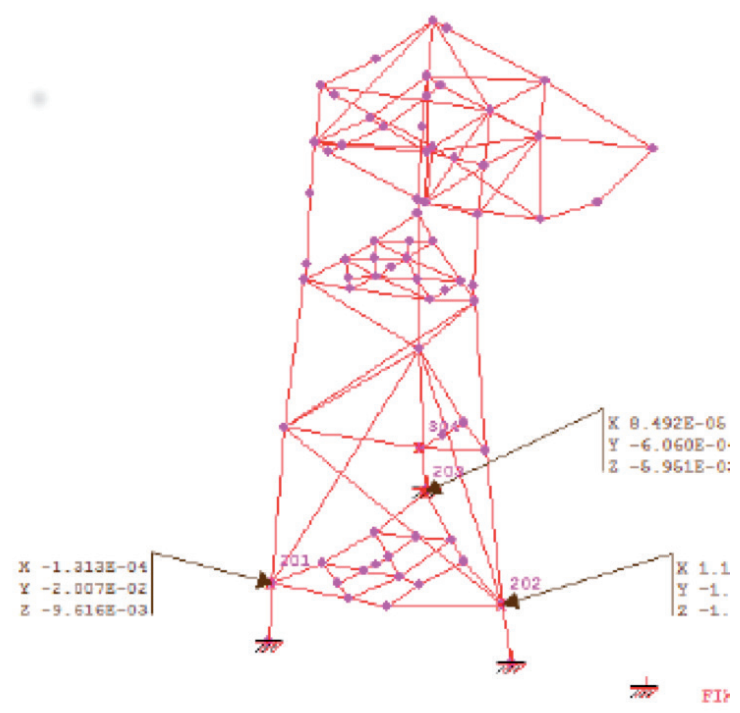

\begin{tabular}{|c|c|c|c|}
\hline Nodo & $\begin{array}{c}\text { Desplazamiento } \\
\text { X (inch) }\end{array}$ & $\begin{array}{c}\text { Desplazamiento } \\
\text { Y (inch) }\end{array}$ & $\begin{array}{c}\text { Desplazamiento } \\
\text { Z (inch) }\end{array}$ \\
\hline 201 & $-0,0001313$ & $-0,02007$ & $-0,009616$ \\
\hline 202 & 0,01123 & $-0,01792$ & $-0,0161$ \\
\hline 203 & 0,0000849 & $-0,000606$ & $-0,005951$ \\
\hline
\end{tabular}

of the loads with the structure, considering also the effects originated by the hydrostatic pressure (Hydrostatic Collapse).

To verify the structural resistance of the elements, a review of the acting efforts is made in the structural elements according to the design standards and criteria, which for our case is APIWSD21, given that it is current in the database of the System used GTStrudl [7].

Table 3. Characteristics of the status of the wave in the Region of Analysis [1].

\begin{tabular}{lr}
\hline \multicolumn{1}{c}{ Definition } & \multicolumn{1}{c}{ Value } \\
\hline Depth $(\mathrm{d})$ & $150 \mathrm{mts}$ \\
\hline Height of wave $(\mathrm{H})$ & $1.6 \mathrm{mts}$ \\
\hline Peak Period $(\mathrm{Tp})$ & $19 \mathrm{sec}$ \\
\hline Drag coefficient $(\mathrm{Cd})$ & 1.0 \\
\hline Inertia Coefficient $(\mathrm{Cm})$ & 2.0 \\
\hline
\end{tabular}

Fig. 7. Code Check of the structure [7].

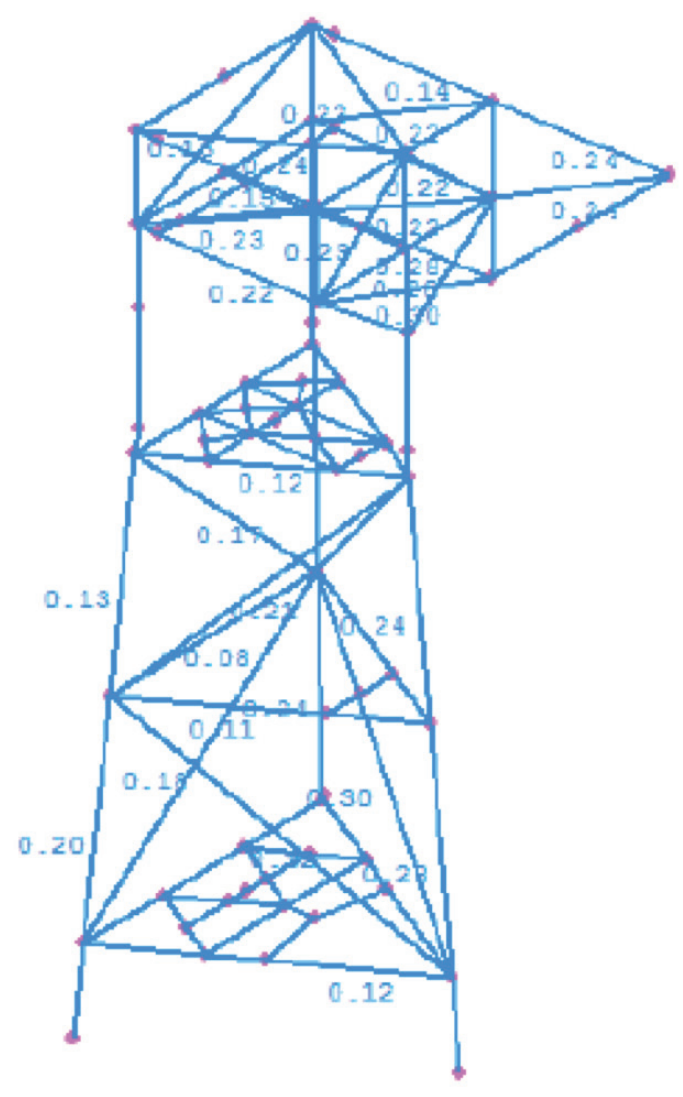




\section{Conclusions}

As there is a need for new discoveries, increase the reserves and the production in the Colombian Caribbean sea at depths up to 300 meters, an increasing development of the infrastructure in offshore platforms type jacket is expected. This research paper proposes a methodology of analysis and structural design considering the theoretical foundations and field information necessary to provide reliable systems type Jacket according to its functionality and the region of location. Information such as the environmental characteristics and the depth of the operating site, become necessary data to select the adequate theoretical foundation for the development of the analysis.

The model of analysis was applied for the design and analysis of a platform type Jacket according to the environmental conditions of Block RC-5 of the Colombian Caribbean sea, complying with the parameters permitted by the design standards for these types of structures. The presented methodology will make make the development of future works easier within the field of study of offshore engineering in the Colombian Caribbean region.

\section{References}

ANDRADE, CARLOS; GARCÍA, CAROLINA: Significant Height of the Waves in the Colombian Caribbean Basin, Radar Altimetry Data. In: Scientific Newsletter CIOH No.29 (2011), September, Nr. 3, p. 27\{45 pages XII, $1,50,67$
BELTRÁN, FRANCISCO; CERROLAZA, MIGUEL: Dynamic Analysis of Structures Subjected to Non Linear Loads. In: International Magazine of Numeric Methods for the Calculation and Design in Engineering (1988) pages XII, 34, 35, 37

AMERICAN PETROLEUM INSTITUTE. Recommended Practice for Planning, Designing and Constructing Fixed Platforms: Load and Resistance Factor Design API 2A-LFRD first edition, 1993 reaffirming May 16, 2003 Section C, p. 26-33

INVEMAR: Experience of INVEMAR in Offshore Exploration and Drilling Studies. In: ANH: Hydrocarbons National Agency (2012) pages XII, 39

PALOMINO, MARÍA; ALMAZÁN, JOSÉ: Description, Measurement and Analysis of waves, Universidad Politécnica de Madrid, Graduation Thesis, 1984. \{Airy Theory pages XII, 33, 38

RODRÍGUEZ, JOSÉ ; RUEDA, JULIO: Modeling of a Fixed Maritime Platform in the Caribbean Round from some established requirements, Universidad Industrial de Santander, Graduation Thesis, 2009 pages XII, 19, 20, 48

System of Finite Elements and Environmental. Loads GTSTRUDL-GTSELOS. 